\title{
Future changes in flash flood frequency and intensity of the Tha Di River (Thailand) based on rainfall-runoff modeling and advanced delta change scaling
}

\section{S. Hilgert, A. Wagner, and S. Fuchs}

Institute for Water and River Basin Management (IWG), Department Aquatic Environmental Engineering (ISWW), Karlsruhe Institute for Technology (KIT), Karlsruhe, Germany

Received: 10 June 2015 - Accepted: 16 July 2015 - Published: 3 August 2015

Correspondence to: A. Wagner (adrian.wagner@ kit.edu)

Published by Copernicus Publications on behalf of the European Geosciences Union.

Future changes in flash flood frequency and intensity of the

Tha Di River

(Thailand)

S. Hilgert et al.

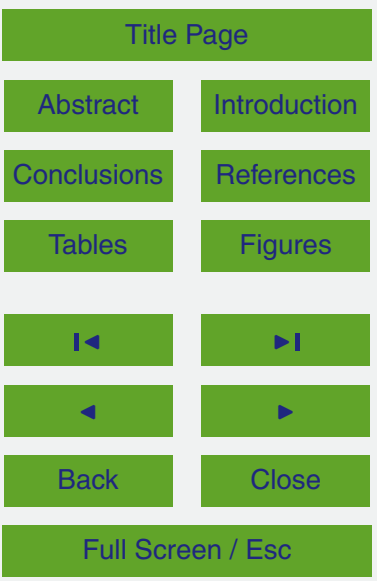

Printer-friendly Version

Interactive Discussion 


\section{Abstract}

As a consequence of climate change, extreme and flood-causing precipitation events are expected to increase in magnitude and frequency, especially in today's highprecipitation areas. During the north-east monsoon seasons, Nakhon Si Thammarat 5 in southern Thailand is flash-flooded every 2.22 years on average. This study investigates frequency and intensity of harmful discharges of the Tha Di River regarding the IPCC emission scenarios A2 and B2. The regional climate model (RCM) PRECIS was transformed using the advanced delta change (ADC) method. The hydrologic response model HBV-Light was calibrated to the catchment and supplied with ADCscaled daily precipitation and temperature data for 2010-2089. Under the A2 (B2) scenario, the flood threshold exceedance frequency on average increases by $133 \%$ (decreases by $10 \%$ ), average flood intensity increases by $3 \%$ (decreases by $2 \%$ ) and the annual top five discharge peaks intensities increase by $46 \%$ (decrease by $5 \%$ ). Yearly precipitation sums increase by $30 \%$ (10\%) towards the end of the century. The

15 A2 scenario predicts a precipitation increase during the rainy season, which intensifies flood events; while increases projected exclusively for the dry season are not expected to cause floods. Retention volume demand of past events was calculated to be up to $12 \times 10^{6} \mathrm{~m}^{3}$. Flood risks are staying at high levels under the B2 scenario or increase dramatically under the A2 scenario. Results show that the RCM scaling process is inflicted with systematic biases but is crucial to investigate small, mountainous catchments. Improvement of scaling techniques should therefore accompany the development towards high-resolution climate models.

\section{Introduction}

Of all natural disasters on a global scale, flooding is the most frequently reported one.

It affects by far the most people (Jonkman, 2005) and is the economically most damaging. Additionally, the population vulnerable to floods is expected to grow (Opperman
HESSD

12, 7327-7352, 2015

Future changes in flash flood frequency and intensity of the

Tha Di River

(Thailand)

S. Hilgert et al.

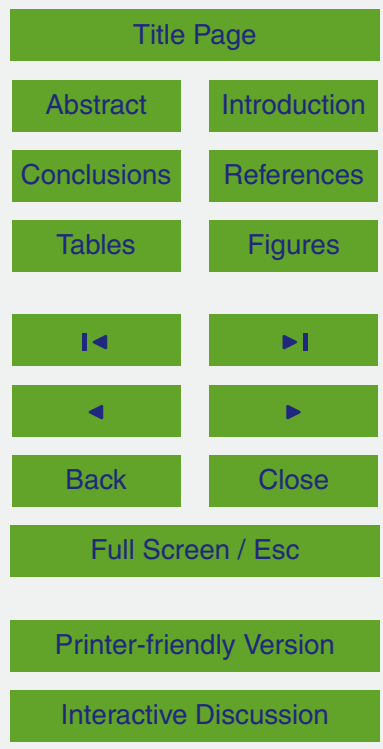


et al., 2009) and despite tremendous efforts in controlling them, flood frequencies and damages are increasing (Kundzewicz und Takeuchi, 1999). Longer-lasting river floods affect the greatest number of people, but short-dated flash floods have by far higher mortalities per event. Of all natural disasters, only earthquakes and droughts killed 5 more people between 1975 and 2002 than freshwater floods (Jonkman, 2005).

Thailand is expected to continue its past trends of increases in mean temperatures and yearly precipitations sums. The Southeast Asia START Regional Center (2010) compared eight General Circulation Model (GCM) results for the period 2045-2065 to recent climate and found an average increase of yearly cumulative precipitation of $1040 \%$ (today: $1857 \mathrm{~mm} \mathrm{yr}^{-1}$; future: $2603 \mathrm{~mm} \mathrm{yr}^{-1}$ ) for the lower coast of the Gulf of Thailand under the intermediate Intergovernmental Panel on Climate Change (IPCC) greenhouse gas emission scenario A1B. Most of the increase is expected for the rainy season. In Thailand, summers will be longer; the winters wetter, shorter and warmer (Christensen et al., 2014). Global warming is generally connected to increasing fre15 quency and intensity of extreme precipitation events (Bates et al., 2008) especially in regions that are already wet today (Sillmann and Roeckner, 2008). This leads to a higher risk of floods. In South-East Asia, numbers and magnitudes of heavy downpours are expected to increase especially during the north-east monsoon season between November and February (Trenberth, 2011).

20 The primary objective of this study is to investigate peak discharges of the Tha Di River as a function of climate change. This includes the determination of thresholds for harmful discharge levels and their exceedance frequencies in past and future climates as well as an improved understanding of the rainfall-runoff relation and flood characteristics in the watershed. The rainfall-runoff model HBV-Light (Berström and Forsman, temperature and evaporation as well as catchment elevation properties to represent the headwaters and middle reaches of the Tha Di Catchment. The model was then supplied with precipitation and temperature data from 2011-2089 following the two IPCC greenhouse gas emission scenarios A2 and B2 (Nakićenović et al., 2000). This

\section{HESSD}

$12,7327-7352,2015$

Future changes in flash flood frequency and intensity of the

Tha Di River

(Thailand)

S. Hilgert et al.

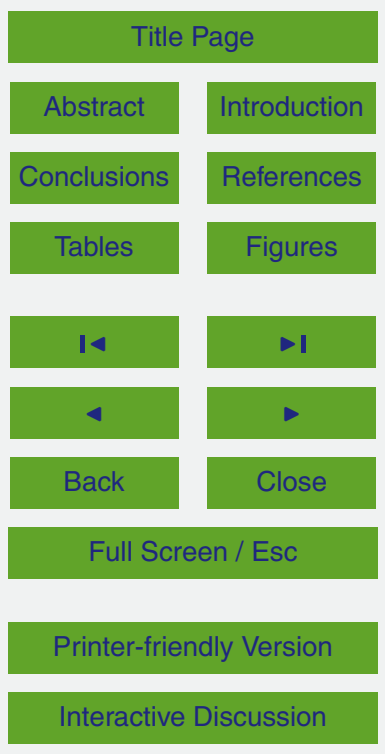

7329 
input data was derived from scaling historical precipitation series by running a modified version of the Advanced Delta Change (ADC) method (van Pelt et al., 2012b) with Regional Climate Model (RCM) PRECIS output (Southeast Asia START Regional Center, 2010). This way, future precipitation and temperature output was generated that com5 plies with the high requirements on spatial resolution resulting from the small size and steep relief of the catchment. Eventually, HBV-Light yielded three discharge series: the base line series derived from observed precipitation as well as two climate change series following the high-emission A2 and low-emission B2 scenario, respectively.

In the following chapter, brief introductions to the study area and to the hydrologic 10 model used are given. Section 3.1 describes the climate and discharge data used as well as the setup of HBV-Light. Then, the ADC method by van Pelt et al. (2012b) and the modifications made to it are outlined in Sects. 3.2 and 3.3 for precipitation and temperature, respectively. Section 3.4 describes how flood return periods and harmful discharge thresholds were determined for the given discharge gauge. Final parameters and goodness-of-fit measures of the hydrologic model are listed in Sect. 4.1. To illustrate the effect of the ADC transformation, raw RCM output is compared to transformed and observed series in Sect. 4.2. After that, trends in future precipitation patterns along the two emission scenarios are shown in Sect. 4.3. Section 4.4 show results of the threshold determination process. Finally, future changes in flood frequency and intensity under consideration of these thresholds and the two emission scenarios are shown in Sect. 4.5. The ability of the modeling approach to express future precipitation and discharge patterns is discussed in Sect. 5.1. Section 5.2 discusses the typical flash flood behavior of past events and points out practical implications from them. In this light, Sect. 5.3 briefly evaluates the modeled results, before conclusions are drawn in 25 Sect. 5.4.

\section{HESSD}

$12,7327-7352,2015$

Future changes in flash flood frequency and intensity of the

Tha Di River

(Thailand)

S. Hilgert et al.

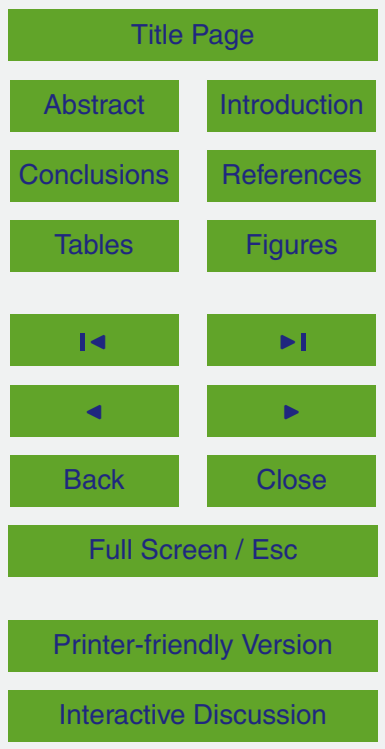




\section{Study area and model}

\subsection{Study area}

The Tha Di River is located in south-east Thailand and drains, after a flow length of $77 \mathrm{~km}$, into the Gulf of Thailand. Its sources are to be found in the densely forested 5 mountains of the Khao Luang National Park whose highest peak reaches 1835 ma.s.l. Moving downstream, land use intensity, stream regulation and population density increase. The City of Nakhon Si Thammarat with about 100000 inhabitants stretches from north-west to south-east, parallel to the coast (Fig. 1). Thus, essentially all the water collected in the headwaters has to pass through the city along many canals and fortified river beds before entering the sea. As a result, flash floods have frequently caused damage to houses and infrastructure. Since 1988, storm water from the Tha Di River in Southern Thailand has severely flooded the City of Nakhon Si Thammarat at least 12 times.

The Tha Di Catchment is characterized by a tropical monsoon climate with year15 round precipitation occurrence, but a distinctly uneven distribution of rainfall. Orographic precipitation during the north-east monsoon season between October and December makes up for $56 \%(1482 \mathrm{~mm})$ of the yearly average rainfall $(2669 \mathrm{~mm})$.

Rainfall-runoff calibration, validation and future simulation conducted in this study are based on discharge measurements of the runoff station "x55" located about $15 \mathrm{~km}$ 20 upstream of the City of Nakhon Si Thammarat. The HBV-Light model therefore represents the $108 \mathrm{~km}^{2}$ large headwater sub-catchment of the total Tha Di Catchment (about $470 \mathrm{~km}^{2}$ ).

\subsection{HBV-Light}

HBV-Light is a semi-distributed, conceptual rainfall-runoff model (Seibert and Vis, 2012). Originally developed for Scandinavian catchments, it has successfully been applied to (mountainous) tropical and sub-tropical watersheds (Andersson et al., 2011;

Future changes in flash flood frequency and intensity of the

Tha Di River

(Thailand)

S. Hilgert et al.

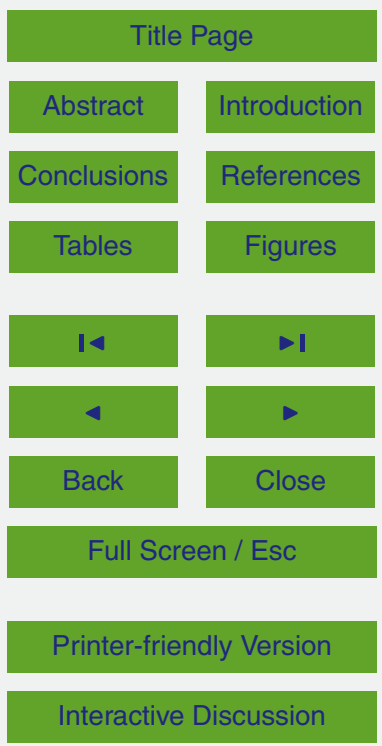


Normand et al., 2011). Here, HBV-Light was run in the standard version and the lake area was set to zero. All snow routine parameters were left to default. Therefore, the water balance Eq. (1) of HBV-Light for a catchment was simplified to (cf. Driessen et al., 2010):

${ }_{5} \quad P-E-Q=\frac{\mathrm{d}}{\mathrm{d} t}[\mathrm{SM}+\mathrm{SUZ}+\mathrm{SLZ}]$

where $P$ is precipitation, $E$ evaporation and $Q$ discharge, all with dimensions $\left[\mathrm{LT}^{-1}\right]$. SM represents the soil moisture box, SUZ the upper groundwater box and SLZ the lower groundwater box, all with dimensions [L].

Only when the simulated runoff in calibration and validation period sufficiently matches the observed discharge, the model can be legitimately applied to compute future discharge from climate change scenario rainfall simulations. Finding optimal values for calibration is often a compromise (Seibert and Vis, 2012), as the model is required to simulate discharges with a great amplitude (Normand et al., 2011).

\section{Data and methods}

\subsection{HBV-Light input and setup}

HBV-Light requires time series of daily precipitation, daily average air temperature and daily (or long-term monthly mean) evaporation as input. For calibration and validation of the model, daily mean discharge measurements are required for the same period. Here, these data requirements are fulfilled for the period of 1989-2009. Observed val-

ADC-processing (3) base line scenario.

Precipitation of five nearby rain gauges was interpolated for the balance point of the catchment using squared Inverse Distance Weighting (IDW). The resulting precipitation

Future changes in flash flood frequency and intensity of the

Tha Di River

(Thailand)

S. Hilgert et al.

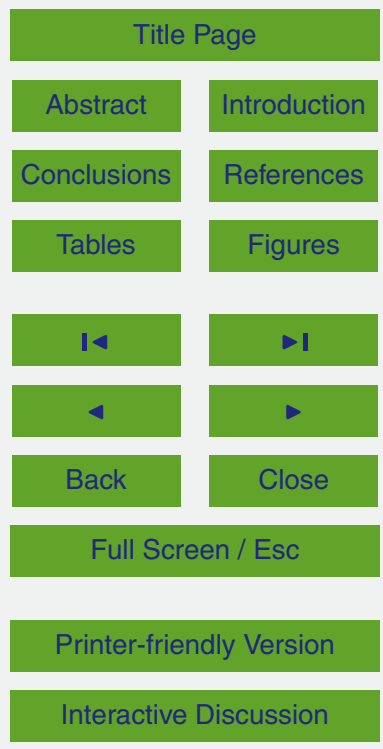

\section{2}


series from 1989-2009 was then used as input for HBV-Light. Together with simultaneously measured discharge at the x55 station, the model was calibrated (1989-2004 period) and validated (2004-2009). The calibration period was chosen to be longer because the model had to run two climate change scenarios and one baseline scenario 5 for a period of 80 years, respectively.

Model parameters were optimized. For HBV-Light, the goodness of fit between simulated and modeled discharge is determined by objective criteria, most commonly by the coefficient of efficiency $R_{\text {eff }}$ (Seibert, 2005). Other criteria included into the optimization were the accumulated differences of precipitation; the efficiency of the model for peak 10 flows; the coefficient of determination $\left(R^{2}\right)$; the efficiency using the natural logarithm of $Q\left(R_{\text {log, eff }}\right)$; as well as visual inspections of the discharge graphs. The search for parameters was aided by hundreds of thousands of random sampling simulations (Monte Carlo method) and parameter set evolution runs (GAP simulations).

Because of the relatively small size of the $x 55$-catchment $\left(108 \mathrm{~km}^{2}\right)$ as well as the ho15 mogenous land use therein, no sub-catchments were created in HBV-Light. However, the IDW-averaged precipitation was interpolated based on the altitude using the areal distribution of the catchment within 18 elevation zones (0-100 to 1700-1800 ma.s.I.) and adding $5.5 \%$ of precipitation for each $100 \mathrm{~m}$-step. This interval, as well as a warmup period of one year (1989-1990 for the control period and 2010-2011 for future projections), are typical configurations of the HBV model.

\subsection{ADC precipitation preprocessing}

Daily modeled PRECIS RCM precipitation and temperature for the A2 and B2 scenario were downloaded for the years 1989-2089 for the grid field representing the Tha Di Catchment (center: Lat $8.4^{\circ} /$ Lon $99.8^{\circ}$ ) (Jintrawet and Chinvanno, 2008). The raw pre25 cipitation output overestimates yearly cumulative rainfall in the catchment by $225 \%$ and significantly underestimates the occurrence of days with more than $100 \mathrm{~mm}$ of precipitation, which are particularly interesting for flood modeling. Therefore, direct forcing of HBV-Light with RCM output was discarded. Instead, the ADC method (van Pelt et al.,

\section{HESSD}

$12,7327-7352,2015$

Future changes in flash flood frequency and intensity of the

Tha Di River

(Thailand)

S. Hilgert et al.

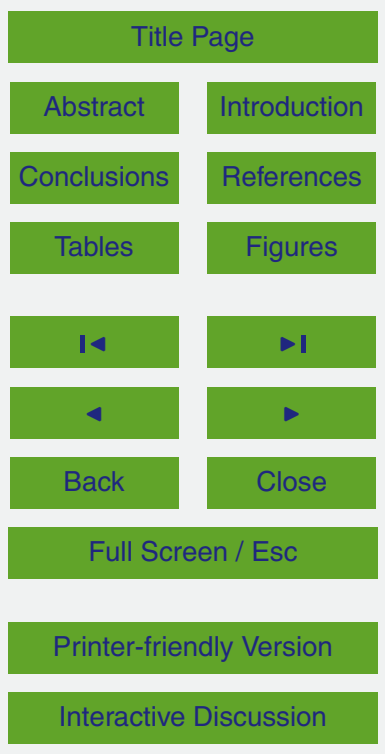


2012b) was applied in order to transfer the climate "signal" of the RCM to the observed precipitation and temperature series. To do so, the ratio between the modeled control series (1990-2009) and the future emission scenario series (2011-2029, 2030-2049, 2050-2069 and 2070-2089) was applied to the observed IDW-averaged series (1990$52009)$ to create the transformed emission scenario precipitation series. The aim was to create a series that is able to express the future climate development inherent in the climate change scenario, while still following the local precipitation patterns observed over 20 years.

While the classical "delta" method considers only mean climate change scenario 10 changes of precipitation using a linear conversion, the ADC method applies a nonlinear transformation and treats precipitation events above the long-term $90 \%$ quantile differently in order to adequately reproduce changes in the extreme. The ADC method was implemented in Microsoft ${ }^{\circledR}$ Excel $^{\circledR} 2010$ SP2 MSO. Two changes from the original approach of van Pelt et al. (2012b) were made: due to the greater skewness of the precipitation probability distribution function, $70 \%$ instead of $60 \%$ quantiles were used for linear scaling and smoothing. Secondly, the transformation was directly applied to daily values rather than using multi-day sums. This was done to account for the quick response time of the catchment, as extreme discharges in the Tha Di result from singleday or multi-hour rain events.

\subsection{ADC temperature preprocessing}

In order to gain plausible values corresponding to the rain distribution while maintaining the climate signal of the regional climate model, observed temperature values were preprocessed as well. Unlike precipitation, observed temperature values were transformed in a linear way using the method described by van Pelt et al. (2012a).
HESSD

$12,7327-7352,2015$

Future changes in flash flood frequency and intensity of the

Tha Di River

(Thailand)

S. Hilgert et al.

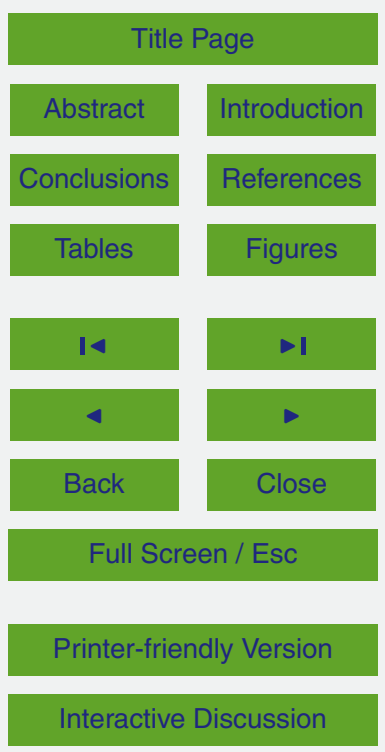




\subsection{Harmful discharge threshold determination}

Eight well-documented flood events with demonstrably negative effects for the local population and economy were compared in order to find threshold values for harmful discharges. After that, their annualities were derived from a cumulative distribution 5 function (CDF), which is based on the extrapolation of observed yearly peak discharges of 38 years by fitting a Generalized Pareto Distribution. To assess the peak underestimation of modeled results, these annualities were then inserted in a second CDF fitted to HBV-modeled yearly peak discharges of the 20 year control period. The corresponding discharges were then used as thresholds to analyze HBV-Light modeled 10 hydrographs.

\section{Results}

\subsection{HBV-Light calibration and validation}

HBV-Light was calibrated and validated with simultaneously recorded discharge and precipitation data of the years 1989-2009. The final parameters are displayed in Table 1 . The model was run to create the modeled base line discharge series from IDW-averaged, observed precipitation as well as the discharge series from ADCtransformed precipitation for the two climate change scenarios. The goodness of the model is commonly examined with the help of objective criteria (Table 2).

\subsection{ADC precipitation preprocessing results}

20 By applying the ADC method, historical precipitation series were lifted or suppressed according to the differences between control and future periods of the RCM PRECIS. The boxplots in Fig. 2 demonstrate the impact of the ADC method on the observed series ("observed IDW"), which was used to calibrate HBV-Light. The transformed series ("A/B2 ADC") were used as input for HBV-Light to model discharges under the influence

\section{HESSD}

12, 7327-7352, 2015

Future changes in flash flood frequency and intensity of the

Tha Di River

(Thailand)

S. Hilgert et al.

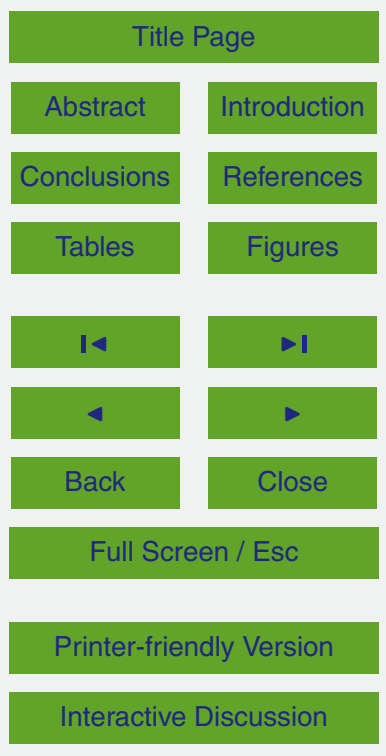


of the corresponding climate change scenarios A2 and B2. The raw RCM series overestimate precipitation sums by the factor of two or more. Furthermore, precipitation peaks are also overestimated. There are few unrealistically high precipitation events and too many in the low to medium range to represent the observed rainfall conditions. 5 In turn, there are not enough precipitation-free days. After applying the ADC method, these biases are corrected for.

\subsection{Tendencies in cumulative precipitation and extreme events}

There is a $30 \%$ increase of yearly average cumulative precipitation for the A2 scenario by the end of the century (Fig. 3). In the B2 scenario, the increase is about $10 \%$. Under both scenarios, January to March are projected to become drier for most modeled periods $(-25 \%$ monthly mean precipitation on average over the entire modeling period). April to August are expected to experience a moderate increase in precipitation $(+21 \%)$. September and October show little change. For the A2 scenario, the already by far wettest and most flood-prone months November and December with high precipitation intensities show a significant rise in monthly mean precipitation (November: $+60 \%$, December: $+69 \%$ ). Under the B2 scenario, means of these months are not expected to significantly change. Accordingly, the number of precipitation events per year exceeding $150 \mathrm{~mm} \mathrm{~d}^{-1}$ is expected to rise by $3 \%$ under B2 and $49 \%$ under the A2 scenario, averaged over the entire modeling period.

\subsection{Harmful discharge thresholds}

To find out which discharges observed at and modeled for the x55 station are negatively affecting the city, hydrographs from recent flood events were evaluated and compared to modeled discharges. All reported floods reached a discharge of at least $150 \mathrm{~m}^{3} \mathrm{~s}^{-1}$, corresponding to an annuality of 2.22 years. While low and mid-level discharges are well-represented by HBV-Light, peaks tend to be underestimated by the model. Consequently, the modeled discharge corresponding to an annuality of 2.22 years is only
HESSD

$12,7327-7352,2015$

Future changes in flash flood frequency and intensity of the

Tha Di River

(Thailand)

S. Hilgert et al.

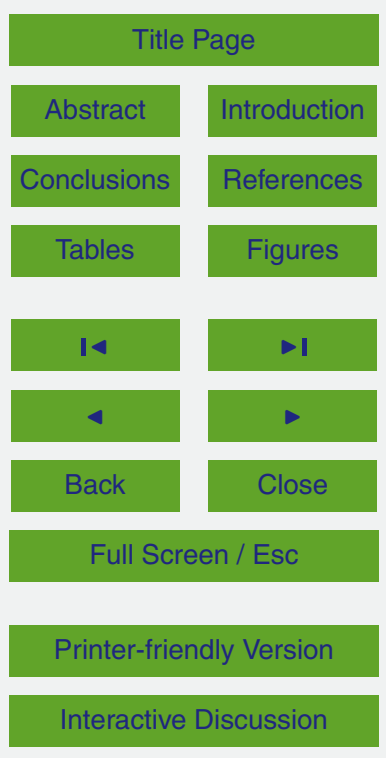


$125 \mathrm{~m}^{3} \mathrm{~s}^{-1}$. Therefore, a modeled discharge greater than $125 \mathrm{~m}^{3} \mathrm{~s}^{-1}$ at the $\mathrm{x} 55 \mathrm{sta}$ tion is considered the threshold for a "harmful" flood (commonly called " $H Q_{2.22}$ "). Additional thresholds for the analyses are $\mathrm{HQ}_{10}\left(209 \mathrm{~m}^{3} \mathrm{~s}^{-1}\right), \mathrm{HQ}_{50}\left(241 \mathrm{~m}^{3} \mathrm{~s}^{-1}\right), \mathrm{HQ}_{100}$ $\left(247 \mathrm{~m}^{3} \mathrm{~s}^{-1}\right)$ and $\mathrm{HQ}_{500}\left(254 \mathrm{~m}^{3} \mathrm{~s}^{-1}\right)$.

\section{$5 \quad 4.5$ Properties of observed and modeled discharges}

The A2 scenario shows higher discharge means and maxima as well as stronger scattering than the observed series (Fig. 4). There is also an increase in mean discharges, median and quantiles towards the end of the century, while modeled maximum values slightly fall. The B2 scenario shows reduced maxima, means and scattering. Highest mean discharges can be observed in the 2030-2049 period, while the more robust 25 and $50 \%$ quantiles steadily rise towards the end of the modeling period.

The development of peak discharges throughout the modeling period is shown in Fig. 5. The range of the top five discharges modeled for each year are shown along with the critical flood thresholds. In the A2 scenario, these peaks are higher than in the base line scenario for all years. The critical thresholds are exceeded more frequently and to a higher degree. There is a slight tendency of decreasing top peaks when moving forward in time. The lower boundary representing the 5th highest peaks in a given year however shows a slight upward trend. In the B2 scenario, especially the top peaks are slightly reduced except for the 2030-2049 period. The lower boundary does not show any significant change to the base line scenario.

Generalized yearly extreme value distributions of climate change scenario discharges show return periods lower than base line under the A2 and higher than the base line under the B2 scenario (Fig. 6). For instance, the $125 \mathrm{~m}^{3} \mathrm{~s}^{-1}$ threshold has a return period of 1.49 years under $A 2$ and 2.68 years under and $B 2$ scenario (base 25 line: 2.22 years) averaged over the entire modeling period. A 100 year discharge is calculated to be $247 \mathrm{~m}^{3} \mathrm{~s}^{-1}$ under the base line, but up to $270 \mathrm{~m}^{3} \mathrm{~s}^{-1}$ under the B2 and up to $310 \mathrm{~m}^{3} \mathrm{~s}^{-1}$ under the A2 scenario.

Future changes in flash flood frequency and intensity of the

Tha Di River

(Thailand)

S. Hilgert et al.

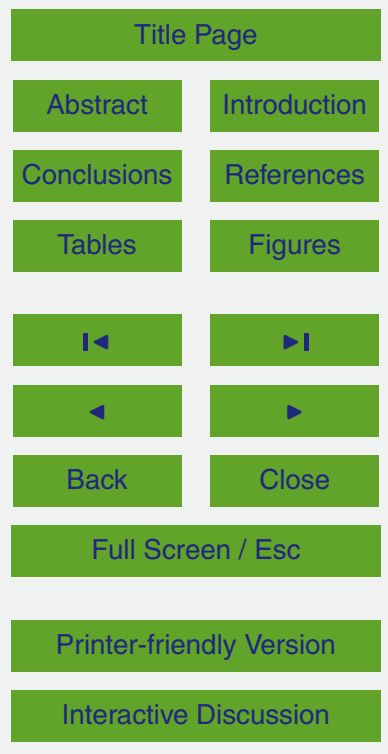


When looking at actual modeled values rather than extrapolates extremes value distributions, there is a $133 \%$ increase in $125 \mathrm{~m}^{3} \mathrm{~s}^{-1}$ threshold exceedance frequency. The B2 scenario shows slightly increased numbers of events in the 2030-2049 period and slightly decreased numbers and intensities in all other periods (overall $10 \%$ 5 decrease in $125 \mathrm{~m}^{3} \mathrm{~s}^{-1}$ threshold exceedances). Similarly, the top 5 highest daily average discharges of each year increase by $46 \%$ on average under the A2 scenario and decrease by $5 \%$ in the $\mathrm{B} 2$ scenario.

\section{Discussion}

\subsection{Model limitations}

10 The RCM is underestimating the precipitation pattern of long dry-spells followed by heavy downpours in the control series. Also, while many authors expect an increase of the extremes with increasing regional temperatures and precipitation means, the raw RCM data shows no clear tendency or even the opposite for the end of the century. It could not be clarified if this dampening of modeled extreme events in later periods is

\section{via the ADC method.}

Modeled discharge peaks are underestimated because heavy downpours in the Khao Luang Mountains, which cause such extreme discharges, are not adequately recorded at the rain gauges in the sub catchment used for calibrating the model. Linear interpolation based on altitude works well for moderate rain events, but is insufficient to account for extreme events. However, this bias was accounted for by selecting the thresholds for harmful floods by aligning the return periods calculated for observed and modeled time series rather than deriving the thresholds directly from absolute (observed) discharge values. This method allows it to not only investigate the future

\section{HESSD}

12, 7327-7352, 2015

Future changes in flash flood frequency and intensity of the

Tha Di River

(Thailand)

S. Hilgert et al.

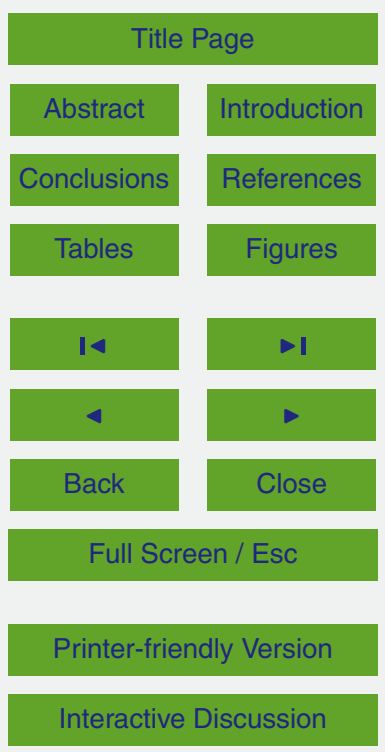


In addition, only limited statements can be made about the harmfulness of a flood event by simply monitoring discharge gauges. Even when the occurrence of snow and ice can be eliminated, the severances of floods depend on more factors than just the river discharge: precipitation intensity, duration, volume, timing, fill levels of over- and 5 underground storage volumes, soil moisture, degree of human encroachment and others influence flood risks (Bates et al., 2008). Even though HBV-Light is able to simulate many of these factors, the critical discharge thresholds used in this study do not cover all events, potentially causing negative effects; not least because of the $15 \mathrm{~km}$ distance of the discharge gauge to the target area. During this distance relevant parameters can - change, which are not represented within the model. What the assumed flood thresholds can provide is a comparative measure, covering events where negative effects definitely arouse, independently from preceding weather and catchment conditions.

Lastly, ADC scaling is afflicted with systematic limitations. Its validity depends on the accuracy of the GCM and of the downscaled RCM used for scaling the observed data, future precipitation patterns in a warmer atmosphere can be approximated by a transformation of observed precipitation series. However, the raw RCM yields a distorted image of the local rainfall patterns, as is apparent from the rainfall distribution differences between observed weather data and RCM-modeled control data of the same period. Although afflicted with a limited ability to account for long-term shifts in seasonality, ADC scaling is able to considerably mitigate this bias. In addition to its low data requirements and computing power, this makes ADC scaling an applicable approach for small catchments.

\subsection{Trigger and properties of Tha Di floods}

25 The City of Nakhon Si Thammarat has been poorly protected from frequent flooding in the past. The threshold for a harmful flood event is exceeded almost every other year. Based on historic flood events, retention volumes of up to $12 \times 10^{6} \mathrm{~m}^{3}$ (March 2011 event) would have been necessary to avert damage for Nakhon Si Thammarat. In ac-

\section{HESSD}

$12,7327-7352,2015$

Future changes in flash flood frequency and intensity of the

Tha Di River

(Thailand)

S. Hilgert et al.

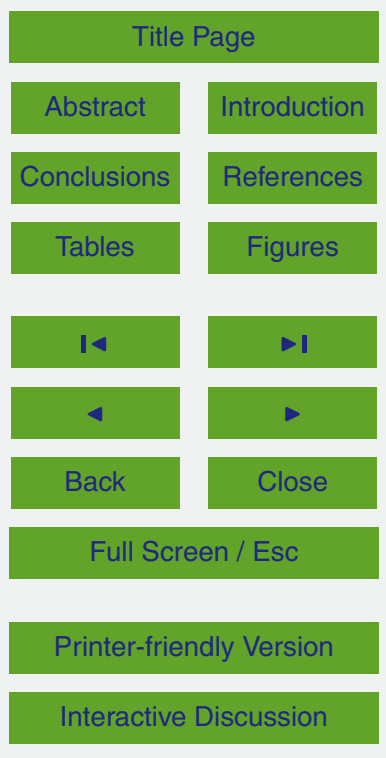


cordance with the monsoon climate of the region, all of the documented flood events occurred between November and the end of March. The catchment reacts quickly to intense precipitation: a harmful flood is usually caused by more than $150 \mathrm{~mm}$ of precipitation falling within $24 \mathrm{~h}$. Steady, multi-day precipitation of moderate rainfall around 50$5100 \mathrm{~mm} \mathrm{~d}^{-1}$ does occur during the rainy season, but is not able to cause harmful discharge levels due to the quick drainage of the catchment. Usually, average discharges are well below the critical threshold at first, even during times of frequent moderate rainfall in winter. Following heavy downpours in the range of $150-220 \mathrm{~mm} \mathrm{~d}^{-1}$, discharges multiply to up to 50 times of the yearly average and drop to initial levels normally within one, in extreme cases with continued precipitation, within three days. Negative consequences of the elevated discharges for the city can persist longer, as the draining of inundated areas cannot begin until the water levels in rivers and canals have sufficiently dropped. This flash flood behavior (Jonkman, 2005) is typical for small, mountainous tropical catchments, where (monsoon-driven) precipitation from large thunderstorms 15

\subsection{Modeled precipitation and discharge}

This study confirms the "wet becoming wetter" tendency of increasing precipitation sums: there is a 30 and $10 \%$ increase of yearly precipitation sums until the end of the century under the ADC-scaled $A 2$ and $B 2$ emission scenarios, respectively. The raw

PRECIS RCM data suggests the two scenarios to show a similar mean annual precipitation in the close future, followed by diverting behavior under increasingly different atmospheric greenhouse gas concentrations towards the end of the century.

However, after ADC-processing, differences in mean precipitation of the A2 and B2 scenarios are large in all simulated periods. This deviation is a consequence of the non-linear nature of the ADC scaling method, with its focus on the correct transfer of changes in the monthly mean; the changes in 70 and $90 \%$ quantiles; as well as the changes in the mean amount of precipitation exceeding the $90 \%$ quantile (van Pelt et al., 2012b). For the A2 scenario, the RCM modeled precipitation increases mainly

HESSD

12, 7327-7352, 2015

Future changes in flash flood frequency and intensity of the

Tha Di River

(Thailand)

S. Hilgert et al.

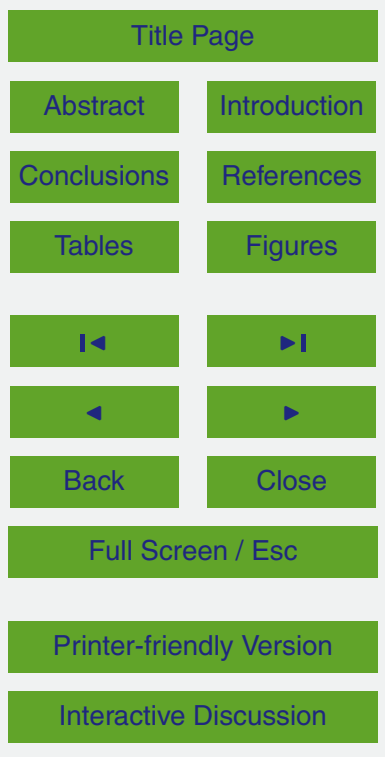


for the wet months November and December, where monthly rainfall is expected to double by the end of the century. Thus, the ADC scaling yields frequent and intense daily rainfall as well as high monthly means. For the B2 scenario however, the RCM predicts moderate precipitation increases almost exclusively for the dry months April to

5 September, where extreme precipitation events and floods are absent in the observed period. Therefore, ADC scaling has a more moderate impact on the observed series, with lower means and lower numbers of extreme precipitation events compared to the A2 scenario.

Modeled future changes in flood frequency and intensity mirror this development: 10 frequency and yearly top five peak intensities, while the B2 scenario intensities and frequencies of extreme events are similar to the historic patterns. The differences between the two scenarios are therefore greater than the differences between different periods of the same scenario. This means that unlike mean discharges and discharge quantiles, which are rising throughout the model period for both scenarios, flood frequencies and intensities do not correlate well with the gradually increasing temperatures and yearly cumulative precipitation foreseen by the model.

\subsection{Conclusions}

The presented results indicate that even for a moderate level of flood security for the 20 City of Nakhon Si Thammarat, substantial flood control measures have to be realized. The future development of discharge behavior depends on the scenario of global warming: under the two scenarios investigated, the flood risk is resting around its current, high state under the low-emission B2 scenario; and becomes dramatically intensified under the high-emission A2 scenario. Rising flash flood intensity as projected under 25 the A2 scenario considerably increases the demand in retention volumes or other flood control measures.

The chain of processing steps may be afflicted with chain of error sources. The peak discharge accuracy of the hydrologic response model can be improved by increas-

\section{HESSD}

$12,7327-7352,2015$

Future changes in flash flood frequency and intensity of the

Tha Di River

(Thailand)

S. Hilgert et al.

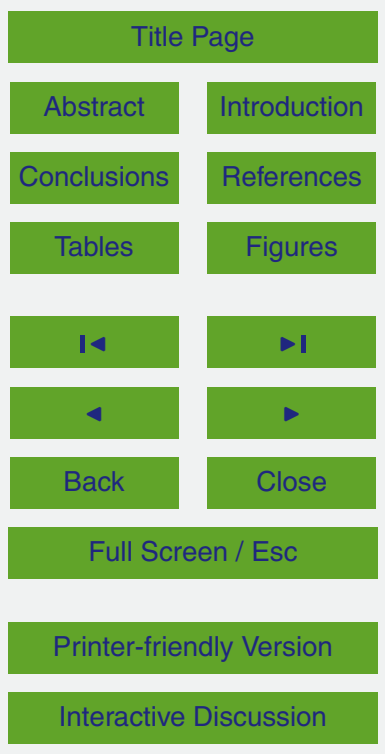


ing the spatial and temporal resolution of rain and runoff measurements. Circulation models are expected to become more accurate as the computing capacities increase. ADC scaling is afflicted with systematic limitations, but will continue to be necessary especially for small, mountainous investigation areas, where RCM resolutions are in5 sufficient. Both ADC scaling and HBV-Light rainfall-runoff modeling have comparatively low input data requirements. Therefore, these methods represent viable tools for the estimation of future flood behavior and can serve as a basis for dimensioning flood control structures.

Acknowledgements. We thank Suthira Thongkao and Pakorn Ditthakit of the School of 10 Engineering and Resources at Wailalak University for kindly providing the necessary input data, supplementary information and valuable advice when conceptualizing the study. We furthermore acknowledge the support by the Deutsche Gesellschaft für Internationale Zusammenarbeit (GIZ) within the Project: 12_II_099_THA_G "Improved flood and draught protection through ecosystem adaption in catchments, Thailand", and Open Access Publishing Fund of

Karlsruhe Institute of Technology.

The article processing charges for this open-access publication were covered by a Research Centre of the Helmholtz Association.

\section{References}

Andersson, L., Samuelsson, P., and Kjellström, E.: Assessment of climate change impact on water resources in the Pungwe river basin, Tellus A, 63, 138-157, doi:10.1111/j.16000870.2010.00480.x, 2011.

Bates, B. C., Kundzewicz, Z., Wu, S., and Palutikof, J.: Climate change and water: technical paper of the Intergovernmental Panel on Climate Change, IPCC technical paper 6, Intergovernmental Panel on Climate Change, Geneva, Switzerland, 214 pp., 2008.

Berström, S. and Forsman, A.: Development of a conceptual deterministic rainfall-runoff model, Nord. Hydrol., 147-170, 1973.

Christensen, J. H., Kanikicharla, K. K., Aldrian, E., An S.-I., Cavalcanti, I. F. A., Castro, M. D., Dong, W., Goswami, P., Hall, A., Kanyanga, J. K., Kitoh, A., Kossin, J., Lau, N.-C., Ren-

\section{HESSD}

$12,7327-7352,2015$

Future changes in flash flood frequency and intensity of the

Tha Di River

(Thailand)

S. Hilgert et al.

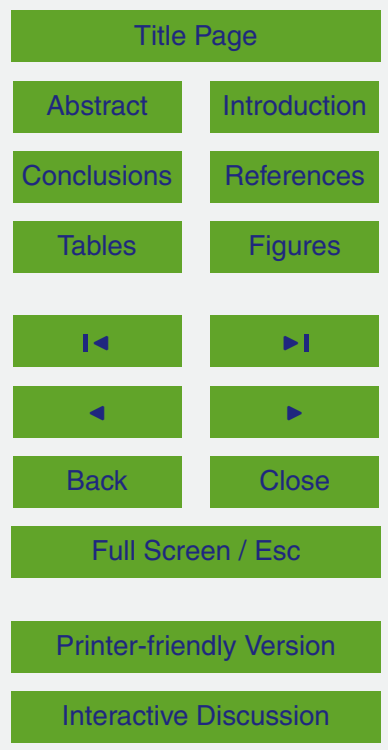


wick, J., Stephenson, D. B., Xie, S.-P., and Zhou, T.: Climate phenomena and their relevance for future regional climate change, in: Climate Change 2013: The Physical Science Basis, Contribution of Working Group I to the Fifth Assessment Report of the Intergovernmental Panel on Climate Change, edited by: Stocker, T. F., Qin, D., Plattner, G.-K., Tignor, M., Allen, S. K., Boschung, J., Nauels, A., Xia, Y., Bex, V., and Midgley, P. M., Cambridge University Press, Cambridge, UK and New York, NY, USA, 1217-1308, 2014.

Driessen, T. L. A., Hurkmans, R. T. W. L., Terink, W., Hazenberg, P., Torfs, P. J. J. F., and Uijlenhoet, R.: The hydrological response of the Ourthe catchment to climate change as modelled by the HBV model, Hydrol. Earth Syst. Sci., 14, 651-665, doi:10.5194/hess-14651-2010, 2010.

Jintrawet, A. and Chinvanno, S.: Climate change in Southeast Asia and assessment on impact, vulnerability and adaptation on rice production and water resource, Final Report for APN Project, Asia-Pacific Network for Global Change Research (APN), Kobe, Japan, 80 pp., 2008.

Jonkman, S. N.: Global perspectives on loss of human life caused by floods, Nat. Hazards, 34 , 151-175, doi:10.1007/s11069-004-8891-3, 2005.

Nakićenović, N., Alcamo, J., Davis, G., Vries, B. D., Fenhann, J., Gaffin, S., Gregory, K., Griibler, A., Jung, T. Y., and Kram, T.: Special report on emissions scenarios: a special report of Working Group III of the Intergovernmental Panel on Climate Change, Cambridge University Press, Cambridge, New York, 599 pp., 2000.

Normand, S., Konz, M., and Merz, J.: An application of the HBV model to the Tamor Basin in Eastern Nepal, J. Hydrol. Meteorol. , 7, 49-58, doi:10.3126/jhm.v7i1.5616, 2011.

Seibert, J.: HBV Light Version 2, User's Manual, Stockholm University Department of Physical Geography and Quaternary Geology, Stockholm, 32 pp., 2005.

Seibert, J. and Vis, M. J. P.: Teaching hydrological modeling with a user-friendly catchmentrunoff-model software package, Hydrol. Earth Syst. Sci., 16, 3315-3325, doi:10.5194/hess16-3315-2012, 2012.

Sillmann, J. and Roeckner, E.: Indices for extreme events in projections of anthropogenic climate change, Climatic Change, 86, 83-104, doi:10.1007/s10584-007-9308-6, 2008.

30 Southeast Asia START Regional Center: Preparation of Climate Change Scenarios for Climate Change Impact Assessment in Thailand, Bangkok, Thailand, 84 pp., 2010.

Trenberth, K. E.: Changes in precipitation with climate change, Clim. Res., 47, 123-138, doi:10.3354/cr00953, 2011.
HESSD

12, 7327-7352, 2015

Future changes in

flash flood frequency and intensity of the

Tha Di River

(Thailand)

S. Hilgert et al.

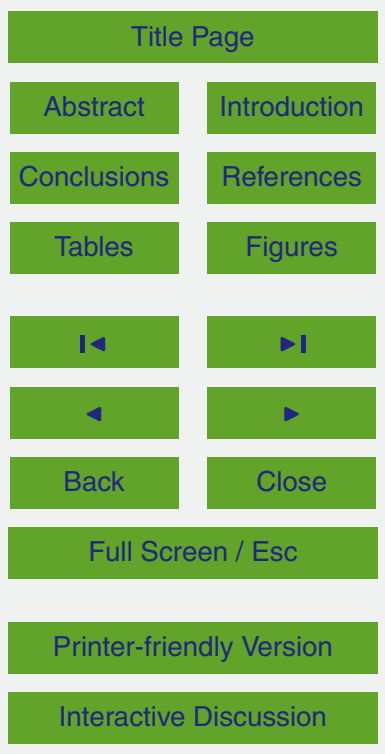


van Pelt, S. C., Beersma, J. J., Buishand, T. A., van den Hurk, B. J. J. M., and Kabat, P.: Future changes in extreme precipitation in the Rhine basin based on global and regional climate model simulations, Hydrol. Earth Syst. Sci., 16, 4517-4530, doi:10.5194/hess-164517-2012, 2012a.

5 van Pelt, S. C., Beersma, J. J., Buishand, T. A., van den Hurk, B. J. J. M., and Kabat, P.: Future changes in extreme precipitation in the Rhine basin based on global and regional climate model simulations, Hydrol. Earth Syst. Sci., 16, 4517-4530, doi:10.5194/hess-164517-2012, 2012b.

\section{HESSD}

12, 7327-7352, 2015

Future changes in flash flood frequency and intensity of the

Tha Di River

(Thailand)

S. Hilgert et al.

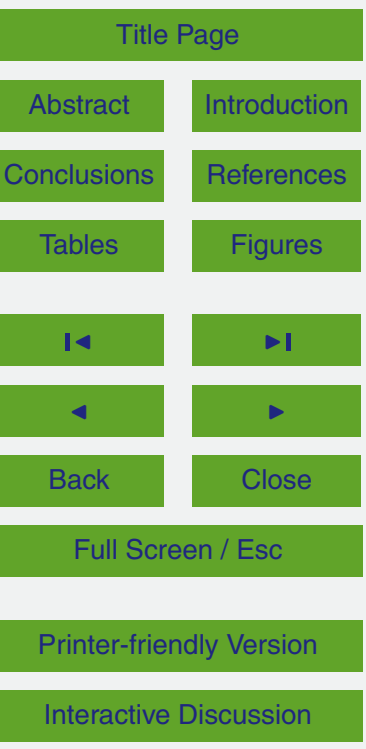


Table 1. HBV-Light model parameters and their optimal values obtained from calibration and validation.

\begin{tabular}{llll}
\hline Parameter & Symbol & Unit & Optimal value \\
\hline Maximum of soil moisture zone & FC & $\mathrm{mm}^{-1}$ & 620 \\
Maximum percolation & PERC & $\mathrm{mmd}^{-1}$ & 17 \\
Threshold for $K_{0}$ to become $K_{1}$ & $\mathrm{UZL}$ & $\mathrm{mm}$ & 80 \\
Evaporation reduction threshold & $\mathrm{LP}$ & - & 0.750 \\
Shape coefficient & $\mathrm{BETA}$ & - & 0.700 \\
Recession coefficient (upper stor.) & $K_{0}$ & $\mathrm{~d}^{-1}$ & 0.830 \\
Recession coefficient (upper stor.) & $K_{1}$ & $\mathrm{~d}^{-1}$ & 0.400 \\
Recession coefficient (lower stor.) & $K_{2}$ & $\mathrm{~d}^{-1}$ & 0.032 \\
Routing parameter & $\mathrm{MAXBAS}$ & - & 2.540 \\
Correction factor for pot. evaporation & $C_{\mathrm{ET}}$ & ${ }^{\circ} \mathrm{C}^{-1}$ & 0.050 \\
Precipitation change by elevation factor & $\mathrm{PC}$ & ${ }_{\mathrm{ALT}} \% 100 \mathrm{~m}^{-1}$ & 5.500 \\
Temperature change by elevation factor & $\mathrm{TC}_{\mathrm{ALT}}$ & ${ }^{\circ} \mathrm{C} 100 \mathrm{~m}^{-1}$ & 0.600 \\
\hline
\end{tabular}

\section{HESSD}

12, 7327-7352, 2015

Future changes in flash flood frequency and intensity of the Tha Di River (Thailand)

S. Hilgert et al.

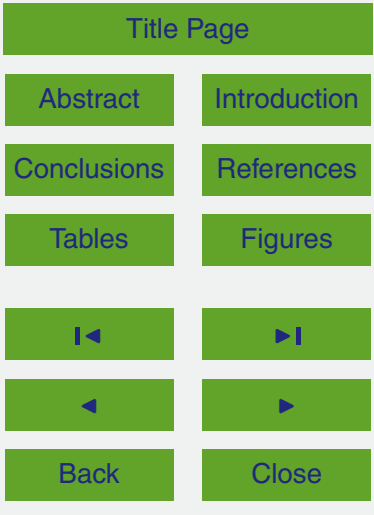

Full Screen / Esc

Printer-friendly Version

Interactive Discussion 
Table 2. HBV-Light objective criteria and their fit for calibration and validation period.

\begin{tabular}{lcll}
\hline Objective criterion & Best fit & Calibration & Validation \\
\hline$R_{\text {eff }}$ & 1 & 0.748 & 0.600 \\
$R_{\text {log, eff }}$ & 1 & 0.610 & 0.293 \\
$R^{2}$ & 1 & 0.749 & 0.694 \\
Peaks efficiency & 1 & 0.584 & 0.752 \\
Mean difference of $Q\left[\mathrm{~mm} \mathrm{yr}^{-1}\right]$ & 0 & 30 & -181 \\
\hline
\end{tabular}

HESSD

12, 7327-7352, 2015

Future changes in flash flood frequency and intensity of the Tha Di River (Thailand)

S. Hilgert et al.

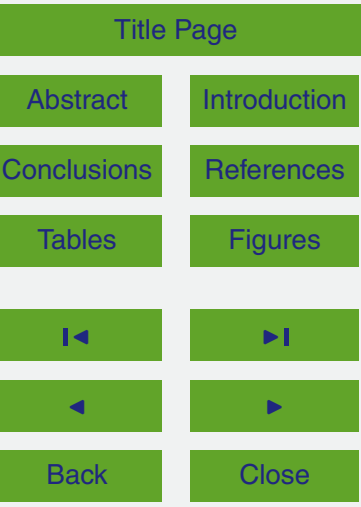

Full Screen / Esc

Printer-friendly Version

Interactive Discussion 


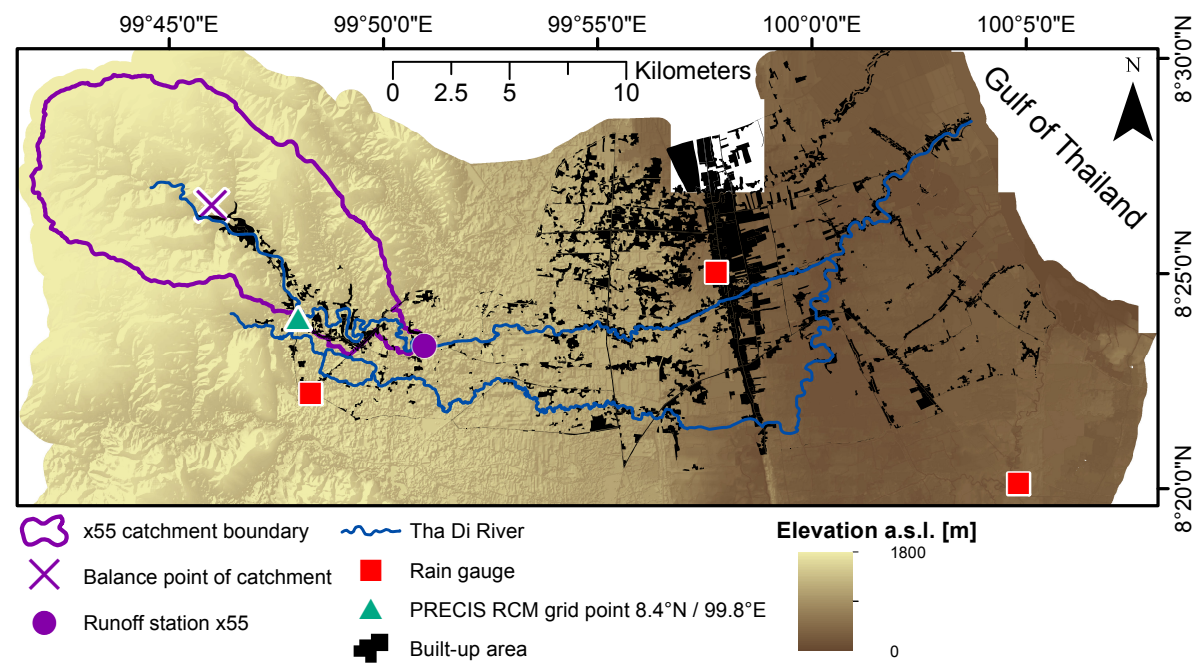

Figure 1. Digital elevation model of the Tha Di Catchment. Also shown are the discharge measuring gauge " $x 55$ " with its corresponding catchment, three of the five rain gauges used for the model calibration, the RCM grid point used for climate change projections as well as the area covered by buildings and roads.

\section{HESSD}

12, 7327-7352, 2015

Future changes in flash flood frequency and intensity of the Tha Di River

(Thailand)

S. Hilgert et al.

\section{Title Page}

14 $\rightarrow 1$

\section{Back}

Close

\section{Full Screen / Esc}

Printer-friendly Version

Interactive Discussion 


\section{HESSD}

12, 7327-7352, 2015

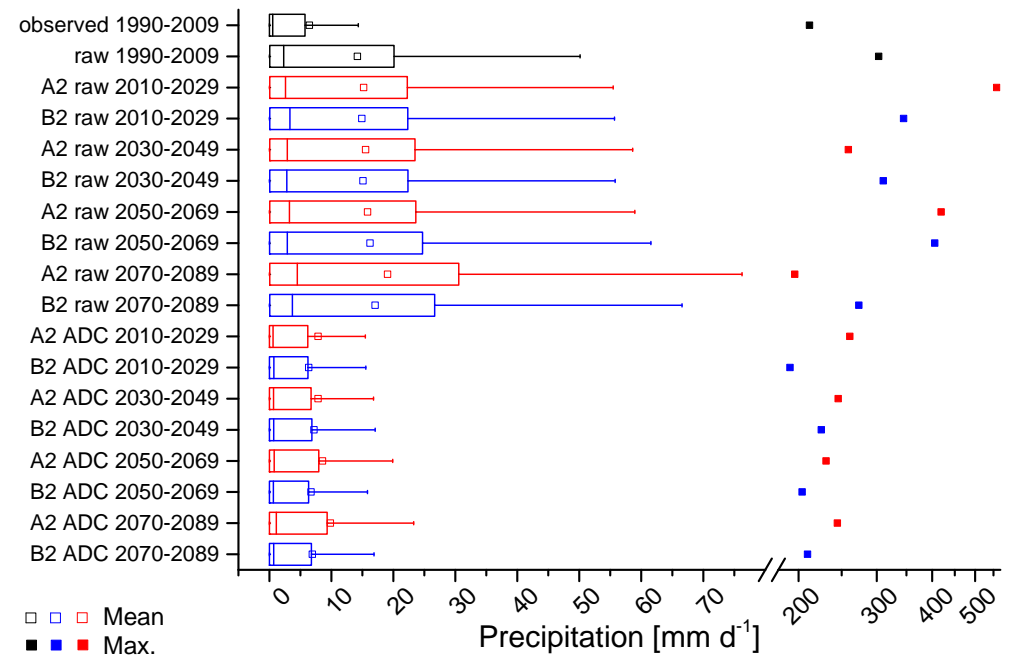

Future changes in flash flood frequency and intensity of the

Tha Di River

(Thailand)

S. Hilgert et al.

\section{Title Page}

\section{Abstract}

Conclusions

Tables

\section{Figures}

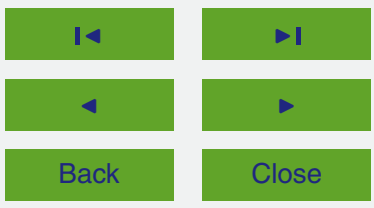

Full Screen / Esc

Printer-friendly Version

Interactive Discussion 


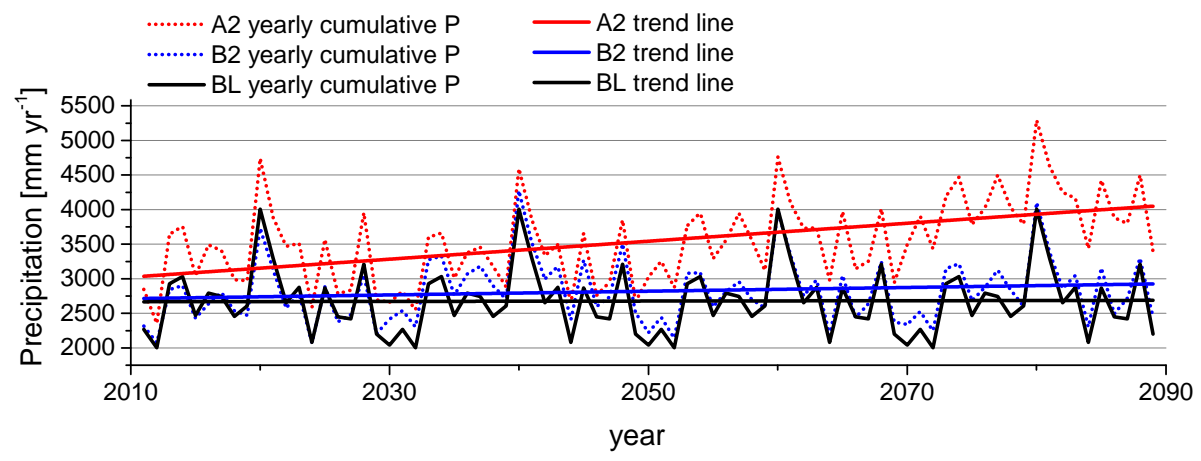

\section{HESSD}

12, 7327-7352, 2015

Future changes in flash flood frequency and intensity of the

Tha Di River

(Thailand)

S. Hilgert et al.

\section{Title Page}

Figure 3. Yearly cumulative altitude-corrected precipitation for observed, IDW-averaged base line $(\mathrm{BL})$ compared to ADC-transformed A2/B2 emission scenarios.

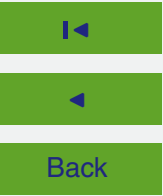

Full Screen / Esc

Printer-friendly Version

Interactive Discussion 


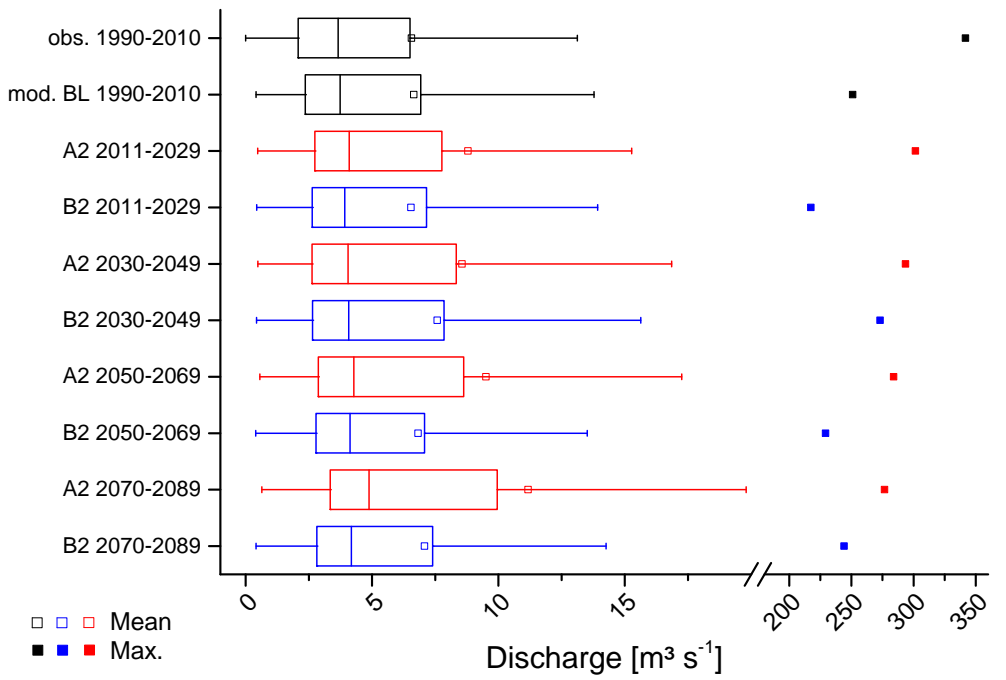

Figure 4. Box plots of modeled base line (BL) and emission scenario (A2/B2) 20 year discharge series. Also shown is the box plot of the observed series. Whiskers denote the lowest datum still within 1.5 interquartile range of the lower quartile.

\section{HESSD}

12, 7327-7352, 2015

Future changes in flash flood frequency and intensity of the Tha Di River

(Thailand)

S. Hilgert et al.

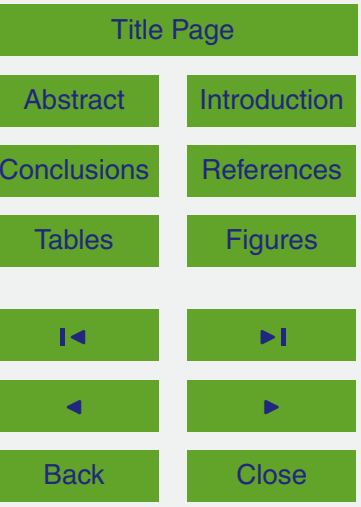

Full Screen / Esc

Printer-friendly Version

Interactive Discussion 


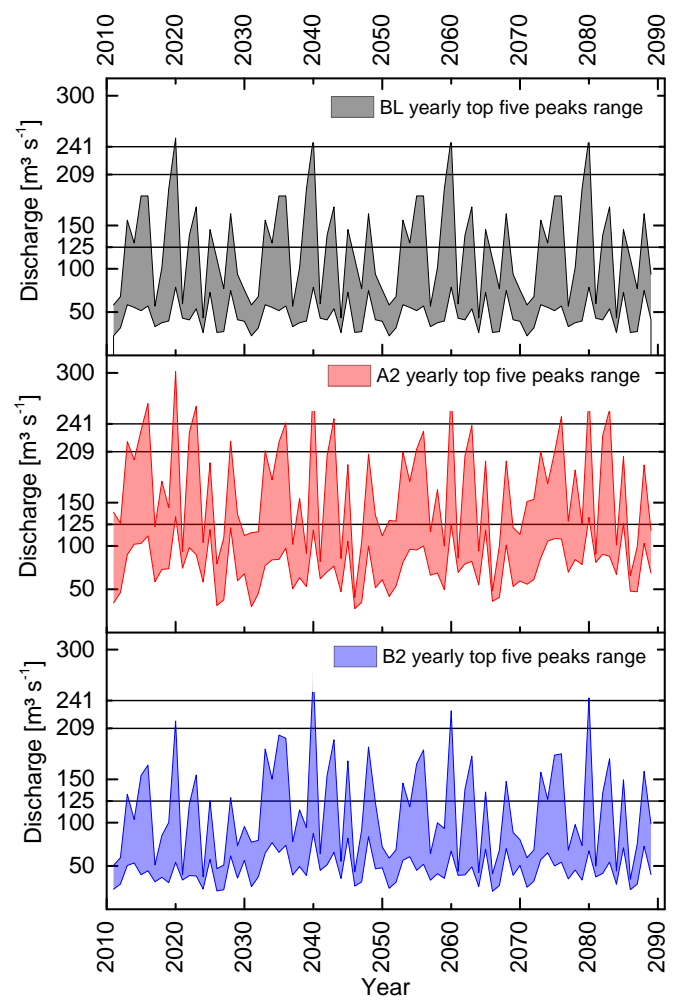

Figure 5. Range of five highest discharges of each year in base line (BL) and A2/B2 emission scenario. Also shown are modeled base line thresholds for 2.22, 10 and 50 year floods (125, 209 and $241 \mathrm{~m}^{3} \mathrm{~s}^{-1}$, respectively).

\section{HESSD}

12, 7327-7352, 2015

Future changes in flash flood frequency and intensity of the

Tha Di River

(Thailand)

S. Hilgert et al.

Title Page

14

Full Screen / Esc

Printer-friendly Version

Interactive Discussion 


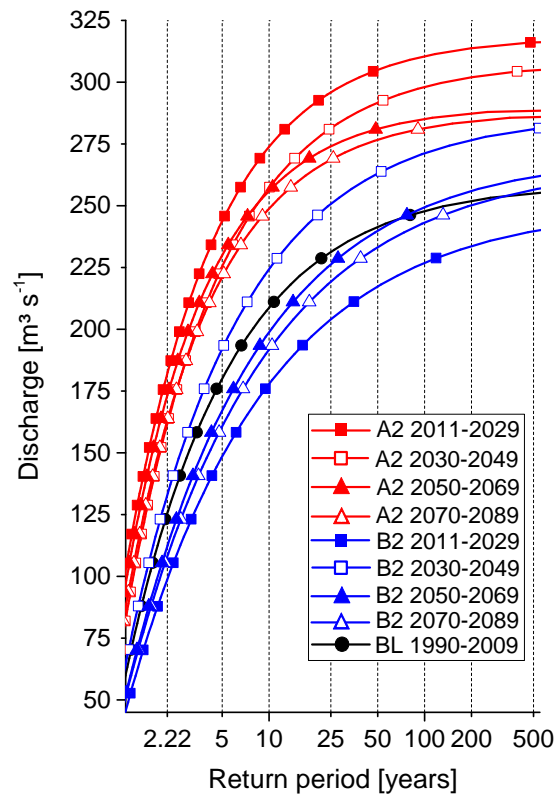

Figure 6. Return periods of modeled base line (BL) and emission scenario (A2/B2) discharges shown as generalized yearly extreme value distributions of 20 year series.

\section{HESSD}

12, 7327-7352, 2015

Future changes in flash flood frequency and intensity of the Tha Di River

(Thailand)

S. Hilgert et al.

\section{Title Page}

Abstract

Conclusions

Tables

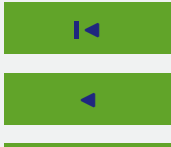

Back
Introduction

References

Figures

$\rightarrow 1$

$>$

Close
Full Screen / Esc

Printer-friendly Version

Interactive Discussion 